\title{
Advances in Mesenchymal Stromal Cell Properties
}

\section{Roberta Rizzo*}

Department of Experimental and Diagnostic Medicine, Section of Microbiology, University of Ferrara, Ferrara, Italy

\begin{abstract}
Human multipotent mesenchymal stromal cells (hMSCs) represent stem cells for non-hematopoietic tissues. The main interest in hMSCs is correlated with their ability to suppress the proliferation of CD8+ T lymphocytes regulating the transplantation rejection. Moreover, hMSCs are able to inhibit the differentiation of dendritic cells, the proliferation and antibody production of $B$ lymphocytes and they stimulate the formation of regulatory $T$ cells. The mechanisms at the basis of MSCs activity need cell-cell interaction and the secretion of soluble molecules into the microenvironment as hepatocyte growth factor, transforming growth factor-beta (TGF-beta), interleukin-10 and -2 (IL-10, IL-2), tumour necrosis factor-alpha (TNF-alpha), prostaglandin E2 (PGE2), indoleamine 2,3-dioxygenase (IDO) and Human Leukocyte Antigen (HLA)-G.
\end{abstract}

Human multipotent mesenchymal stromal cells (hMSCs), first described by Friedenstein in ' 70 years [1] as non-hematopoietic cell precursors with osteogenic potential, represent stem cells for nonhematopoietic tissues [2]. The International Society for Cellular Therapy (ISCT) reviewed the functional and immunophenotypic characteristics of stromal cells [3]: they are plastic adherent cells that retain in vitro clonogenic potential, defined by the presence of the fibroblast-colony forming unit (CFU-F), capable of supporting hematopoiesis and having differentiation ability towards different cell types, as osteoblasts, chondrocytes, adipocytes, myocytes [4]. In vitro and in vivo studies showed that hMSCs could differentiate into cells of non-mesodermal origin such as neurons, skin and gut epithelial cells, hepatocytes and pneumocytes [5]. They express surface makers CD73, CD90, and CD105, and lack of expression of stem cell antigens CD34 and CD45 [3].

hMSC were initially isolated and characterized from the bone marrow, but further researches identified other sources such as amniotic membrane, skin, adipose tissue, cord blood, fetal liver, placenta and synovium [6]. Although these hMSC were thought to be the same general cell population regardless of the tissue source, recent data suggested a different hMSC gene expression profile on the basis of their tissue origin, indicating that hMSC tissue heterogeneity is biologically relevant.

In the last years several studies demonstrated the peculiar immuno logical characteristics of hMSCs, as low antigenic ity, caused by the decreased expression of classical HLA (human leukocyte antigen) class I molecules and the complete absence of HLA class II antigens and co-stimulatory molecules as CD80 (B7-1), CD86 (B7-2) and CD40, and high immune-modulatory ability. hMSCs suppress the proliferation of T lymphocytes [7], are res istant to the CD8+ T lymphocyte cytotoxic ity, inhibit the differentiation of dendritic cells, the proliferation and antibody production of $\mathrm{B}$ lymphocytes and stimulate the formation of regulatory $\mathrm{T}$ cells. The mechanisms at the basis of hMSCs activity need cell-cell interaction and the secretion of soluble molecules in the micro-environment, as hepatocyte growth factor, transforming growth factor-beta (TGF-beta), interleukin-10 and -2 (IL-10, IL-2), tumour necrosis factor-alpha (TNF-alpha), prostagland in E2 (PGE2), indoleamine 2,3-dioxygenase (IDO) [8] and HLA-G antigens [9].

An entire field of medicine now stakes all on hMSC multipotent capabilities for regenerative medicine, cell therapies and immunosuppressive treatments.

To date, administration of hMSC proved to be safe and efficacious in a variety of disorders [10]: ectodermal regeneration into epidermal cells; neural differentiation into neural-glial cells; mesodermal regeneration, especially bones, cartilage, tendons and muscles; endodermal regeneration into hepatic differentiation and regeneration of resident insulin-producing cells in diabetes; hematopoietic reconstitution with co-transplantation of adipose tissue-derived hMSC with bone marrowderive hematopoietic stem cells; cardiomyocytes differentiation with 5-azacytidine treatment or by spontaneous differentiation of adiposetissue derived hMSC into beating cardiomyocytes reducing infarct size; kidney disorders, involving both ischemic/inflammatory and immunological injury, where hMSCs infusion can promote cellular repair, tissue remodeling with an enhanced recovery of renal functions. Relevant preclinical studies with hMSCs have shown that hMSCs exert potent immunosuppressive effect in vitro and in vivo for inflammatory and autoimmune diseases such as Chron's disease and graft versus host disease (GvHD). In particular, in the context of a steroid-resistant acute GvHD, where the patient could have a fatal outcome weeks or months later, the administration of hMSCs to manage this life-threatening condition resulted feasible, despite the limited and not standardized preclinical available data [11].

hMSCs-mediated tissue regeneration is a promising approach for tissue repair. hMSC in three-dimensional (3-D) biocompatible and biodegradable scaffolds could interact with the damaged area, generating and replacing injured tissues.

The gene transfer into hMSCs and their ability to migrate to a lesion provided evidences for a possible use of hMSCs in clinical application. hMSCs were successfully transfected with bone morphogenetic protein (BMP-2), involved in cartilage formation, and injected in articular fractures [12]. Transplantation of IL-7 gene-engineered hMSCs into lethally irradiated mice led to significant increase in thymopoiesis and protected from GvHD [13].

It is to note that recent concerns have been expressed about the potential transformation of hMSC during the culture process before infusion and the possible implication in tumor development due to their immunosuppressive capacities. The nature and the role of hMSCs

*Corresponding author: Roberta Rizzo, Department of Experimental and Diagnostic Medicine, Section of Microbiology, University of Ferrara, Via Luigi Borsari, 46, I-44121 Ferrara, Italy, Tel: ++390532455382; Fax: ++390532974470; E-mail: rbr@unife.it

Received July 21, 2020; Accepted July 23, 2020; Published July 26, 20120

Citation: Rizzo R (2020) Advances in Mesenchymal Stromal Cell Properties. J Transplant Technol Res 2:e112. doi:10.4172/2161-0991.1000e112

Copyright: (c) 2020 Rizzo R. This is an open-access article distributed under the terms of the Creative Commons Attribution License, which permits unrestricted use, distribution, and reproduction in any medium, provided the original author and source are credited. 
in their micro-environmental niche should be further explored. Moreover, although it has been demonstrated that ex vivo expansion processing of hMSCs is feasible and should be obtained according to good manufacturing practice (GMP) and regulation constraints, definitive standards to produce clinical grade hMSCs are still lacking.

In conclusion, a number of issues still need to be solved before hMSC use in the clinics. In fact, it is still unclear whether hMSCs contribute to tissue repair by differentiation into tissue-specific cell types, or mediate a paracrine effect. Moreover, the anatomical sites, donor type (normal vs pathological), culture expansion conditions, should be carefully considered as an important step before using hMSC for clinical purposes before reinfusion after ex vivo expansion.

\section{References}

1. Friedenstein AJ, Chailakhyan RK, Lalykina KS (1970) The development of fibroblast colonies in monolayer cultures of guinea pig bone marrow and spleen cells. Cell Tissue Kinet 3: 393-403.

2. Prockop DJ (1997) Marrow stromal cells as stem cells for non-hematopoietic tissues. Science 276: 71-74.

3. Dominici M, Le Blank K, Mueller I, Slaper-Cortenbach I, Marini F, et al. (2006) Minimal criteria for defining multipotent mesenchymal stromal cells. The International Society for Cellular Therapy position statement. Cytotherapy 8: 315-317.

4. Owen M, Friedenstein AJ (1988) Stromal stem cells: marrow-derived osteogenic precursors. Ciba Found Symp 136: 42-60.
5. Reyes M, Lund T, Lenvik T, Aquiar D, Koodie L, et al. (2001) Purification and ex vivo expansion of postnatal human marrow mesodermal progenitor cells. Blood 98: 2615-2625.

6. Conget PA, Minguell JJ (1999) Phenotypical and functional properties of human bone marrow mesenchymal progenitor cells. J Cell Physiol 181: 67-73.

7. TseWT, Pendleton JD, Beyer WM, Egalka MC, Guinan EC (2003) Suppression of allogeneic T-cell proliferation by human marrow stromal cells: implications in transplantation. Transplantation 75: 389-397.

8. Meisel R, Zibert A, Laryea M, Gobel U, Daubener W, et al. (2004) Human bone marrow stromal cells inhibit allogeneic $T$-cell responses by indoleamine 2,3-dioxygenase-mediated tryptophan degradation. Blood 103:4619-4621.

9. Rizzo R, Campioni D, Stignani M, Melchiorri L, Bagnara GP, et al. (2008) A functional role for soluble HLA-G antigens in immune modulation mediated by mesenchymal stromal cells. Cytotherapy 10: 364-375.

10. Lanza F, Campioni D, Mauro E, Pasini A, Rizzo R (2012) Immunosoppressive properties of mesenchymal stromal cells. In: Baharvand H, Aghdami (Eds) Advances in stem cell research: Stem cell biology and regenerative medicine. Humana Press, New York 281-301.

11. Le Blanc K, Frassoni F, Ball L, Locatelli F, Roelofs H, et al (2008) Mesenchymal stem cells for treatment of steroid resistant, severe, acute graft-versus-host disease: a phase II study. Lancet 371: 1579-1586.

12. Zachos T, Diggs A, Weisbrode S, Bartlett J, Bertone A (2007) Mesenchymal stem cells mediated gene delivery of bone morphogenetic protein-2 in an articular fracture model. Mol Ther 15:1543-1550.

13. Caplan Al (2007) Adult mesenchymal stem cells for tissue engineering versus regenerative medicine. J Cell Physiol 213: 341-347. 